\title{
Human lipodystrophies linked to mutations in A-type lamins and to HIV protease inhibitor therapy are both associated with prelamin A accumulation, oxidative stress and premature cellular senescence
}

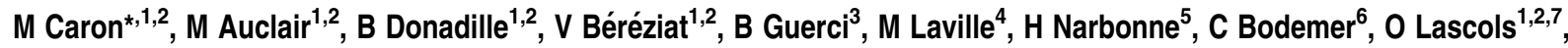 \\ $\mathrm{J}_{\mathrm{Capeau}}{ }^{1,2,8}$ and C Vigouroux ${ }^{1,2,8}$
}

\begin{abstract}
Lipodystrophic syndromes associated with mutations in LMNA, encoding A-type lamins, and with HIV antiretroviral treatments share several clinical characteristics. Nuclear alterations and prelamin A accumulation have been reported in fibroblasts from patients with LMNA mutations and adipocytes exposed to protease inhibitors ( $\mathrm{PI})$. As genetically altered lamin A maturation also results in premature ageing syndromes with lipodystrophy, we studied prelamin $A$ expression and senescence markers in cultured human fibroblasts bearing six different LMNA mutations or treated with PIs. As compared to control cells, fibroblasts with LMNA mutations or treated with PIs had nuclear shape abnormalities and reduced proliferative activity that worsened with increasing cellular passages. They exhibited prelamin A accumulation, increased oxidative stress, decreased expression of mitochondrial respiratory chain proteins and premature cellular senescence. Inhibition of prelamin A farnesylation prevented cellular senescence and oxidative stress. Adipose tissue samples from patients with LMNA mutations or treated with PIs also showed retention of prelamin A, overexpression of the cell cycle checkpoint inhibitor p16 and altered mitochondrial markers. Thus, both LMNA mutations and PI treatment result in accumulation of farnesylated prelamin A and oxidative stress that trigger premature cellular senescence. These alterations could participate in the pathophysiology of lipodystrophic syndromes and lead to premature ageing complications.
\end{abstract}

Cell Death and Differentiation (2007) 14, 1759-1767; doi:10.1038/sj.cdd.4402197; published online 6 July 2007

Mutations in the $L M N A$ gene encoding A-type lamins cause inherited laminopathies, including lipodystrophies with metabolic alterations and early cardiovascular disease, and premature ageing syndromes (reviewed by Mattout et $a l^{1}$ ). LMNA-linked lipodystrophies and progeroid syndromes form a clinical continuum of related phenotypes. ${ }^{2-8}$ Otherwise, HIV-infected patients receiving antiretroviral therapy frequently develop a lipodystrophy syndrome associated with a high risk of metabolic and cardiovascular complications. ${ }^{9}$ These patients also face a growing number of other agerelated comorbidities, such as neurodegeneration, osteopenia and malignancies. ${ }^{10}$

A-type lamins are nuclear proteins required for the structural and functional integrity of the nucleus. Lamin $A$ is translated as a protein precursor that undergoes several maturation steps, including the addition of a C-terminal farnesyl residue, which is subsequently removed by proteolytic cleavage (reviewed by Mattout et $a l^{1}$ ). Defective physiological maturation of prelamin $A$ is the main pathophysiological mechanism underlying several premature ageing syndromes, including the Hutchinson-Gilford progeria syndrome (HGPS) (reviewed by Young et $\mathrm{al}^{11}$ ). Several studies have convincingly demonstrated that the retention of the farnesylated residue confers toxic properties to the partially processed prelamin A. ${ }^{11-13}$ Both cellular abnormalities ${ }^{14-17}$ and premature ageing phenotype in mice ${ }^{18}$ are significantly improved by using drugs that inhibit prelamin A farnesylation.

The HIV antiretroviral protease inhibitors (PIs) indinavir and nelfinavir impede prelamin $A$ maturation in cultured adipocytes, ${ }^{19,20}$ and induce nuclear alterations similar to those observed in LMNA-mutated fibroblasts. ${ }^{19,21}$ Interestingly, these alterations occur in fibroblasts from patients with

\footnotetext{
${ }^{1}$ INSERM, U680, Paris, F-75012 France; ${ }^{2}$ Université Pierre et Marie Curie-Paris6, Faculté de Médecine, UMRS680, Paris, F-75005 France; ${ }^{3}$ Hôpital Jeanne d'Arc, Service de Diabétologie, Endocrinologie et Nutrition, CHU Nancy, France; ${ }^{4}$ Centre de recherche en Nutrition Humaine, Hospices Civils, Lyon, France; ${ }^{5}$ AP-HM, Hôpital La Timone, Service de Nutrition, Maladies Métaboliques, Endocrinologie, Marseille, France; ${ }^{6}$ AP-HP, Hôpital Necker-Enfants Malades, Service de Dermatologie, Paris, France; ${ }^{7}$ AP-HP, Hôpital Saint-Antoine, Département de Biologie Moléculaire, Paris, France and ${ }^{8}$ AP-HP, Hôpital Tenon, Service de Biochimie et Hormonologie, Paris, France

${ }^{*}$ Corresponding author: M Caron, Inserm U680, Faculté de Médecine Pierre et Marie Curie, Site Saint-Antoine, 27 rue Chaligny, 75571 Paris Cedex 12

Tel: + 331400114 84; Fax: + 331400113 52; E-mail: caron@st-antoine.inserm.fr

Keywords: lamin A; prelamin A; HIV protease inhibitors; oxidative stress; mitochondria; cellular senescence; farnesylation

Abbreviations: BrdU, bromodeoxyuridine; CPDL, cumulative population doubling level; DAPI, diamidino-2phenylindole hydrochloride; COX2, cytochrome oxidase complex IV subunit II; COX4, cytochrome oxidase complex IV subunit IV; DMSO, dimethyl sulfoxide; ERK, extracellular-regulated kinase; FBS, fetal bovine serum; FITC,

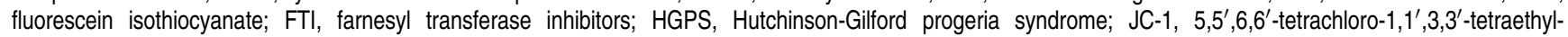
benzimidazolo carbocyanine iodide; MTR, MitoTracker Red 580 probe; NBT, nitroblue tetrazolium; PDL, population doubling level; PI, HIV protease inhibitor; ROS, reactive oxygen species; SA- $\beta$-galactosidase, senescence-associated $\beta$-galactosidase; X-gal, 5 -bromo-4-chloro-3-indolyl- $\beta$-D-galactoside

Received 11.1.07; revised 17.5.07; accepted 17.5.07; Edited by G Kroemer; published online 06.7.07
} 
LMNA-linked lipodystrophies and premature ageing syndromes (reviewed by Mattout et $a l^{1}$ ).

These data let us to suspect that lipodystrophic syndromes related to $L M N A$ mutations or $\mathrm{PI}$ treatment could be considered as, respectively, genetic and acquired laminopathies, and could share common pathophysiological mechanisms, including premature cellular senescence.

Senescence, defined as a series of cellular changes associated with ageing, ${ }^{22-24}$ results from a signal transduction program leading to irreversible arrest of cell growth and a distinct set of changes in the cellular phenotype. Cellular senescence can be induced prematurely by various agents and stimuli, including oxidative stress. ${ }^{25}$ The free-radical theory of ageing postulates that the production of intracellular reactive oxygen species (ROS) is the major determinant of lifespan. ${ }^{26}$ Abundant evidence also implicates mitochondrial changes in the ageing process. ${ }^{26,27}$

Human fibroblasts offer a good model for studying the cellular ageing process in vitro. ${ }^{28}$ In primary culture, fibroblasts proliferate readily but have a limited proliferative potential, ultimately leading to a state of replicative senescence. Senescent fibroblasts show irreversible growth arrest, but remain viable for extended periods of time. They are characterized by their distinct morphology, expression of senescence-associated $\beta$-galactosidase (SA- $\beta$-galactosidase) activity ${ }^{29}$ and upregulation of cell cycle checkpoint inhibitors. ${ }^{25,30}$

In this study, we used primary cultures of skin fibroblasts originating from lipodystrophic patients bearing LMNA mutations, or control fibroblasts treated with indinavir or nelfinavir in vitro and patients' adipose tissue biopsies. We showed that all conditions were associated with defective prelamin A processing and triggered cellular premature senescence, which was prevented by inhibition of prelamin A farnesylation. Mitochondrial alterations and oxidative damage resulting from the toxicity of partially processed prelamin A could, at least in part, underlie the premature senescence phenotype.

\section{Results}

Human fibroblasts with LMNA mutations or treated with PIs have similar nuclear shape abnormalities and overexpress prelamin A. Fibroblasts with LMNA mutations (heterozygous mutations D47Y, L92F, L387V, $\mathrm{R} 399 \mathrm{H}, \mathrm{L} 421 \mathrm{P}$ and $\mathrm{R} 482 \mathrm{~W}$ ) originated from patients with insulin resistance and/or lipodystrophy, as described in Materials and methods. Nuclear shape abnormalities increased during successive passages, affecting up to 40$60 \%$ of total nuclei in fibroblasts with $L M N A$ mutations or treated with PIs (Figure 1a and b). The nuclear abnormalities were similar in the different conditions, except in D47Y LMNA-mutated cells, originating from the only patient exhibiting clinical signs of accelerated ageing, in which the nuclei were more markedly lobulated (Figure 1a). Lamin B staining was reduced in nuclear blebs, affecting $20-40 \%$ of abnormally shaped nuclei in both fibroblasts with LMNA mutations or treated with PIs (Figure 1a).

While prelamin A expression, assessed with a prelamin Aspecific antibody (SC-6214) was barely detected in control

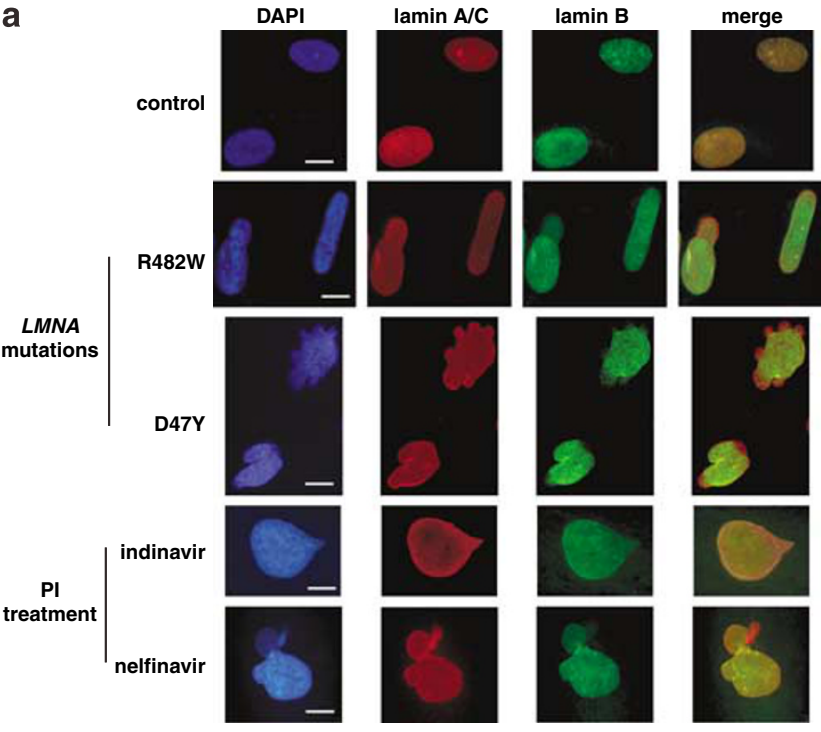

b

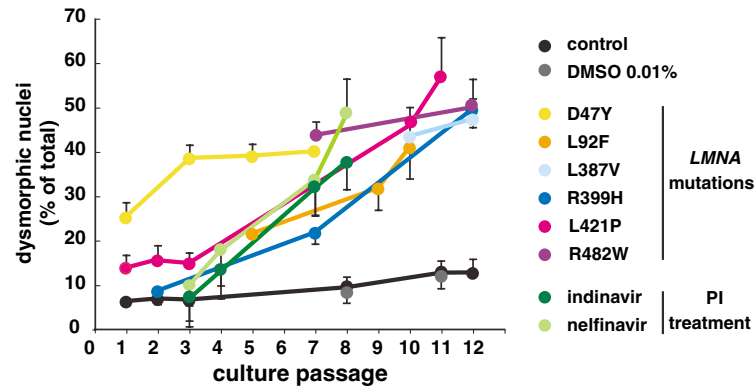

Figure 1 Fibroblasts with LMNA mutations or treated with PIs present similar nuclear dysmorphies. (a) Control fibroblasts and those with LMNA mutations or treated with PIs were fixed and labeled with DAPI, anti-lamin A/C (MAB-3211) and anti-lamin $B$ antibodies before analysis by immunofluorescence microscopy. Nuclei showing one or several blebs or a stick-like morphology were considered dysmorphic. The same types of abnormality were observed in indinavir- and nelfinavir-treated cells, as well as in fibroblasts bearing the six different $L M N A$ mutations studied, with the exception of LMNA-D47Y mutated cells, which showed highly lobulated nuclei. The most representative cells are shown. Twenty to forty percent of the dysmorphic nuclei of fibroblasts with $L M N A$ mutations or treated with PIs, but none in control fibroblasts, showed decreased or absent lamin B staining in the nuclear blebs and poles. Scale bars represent $10 \mu \mathrm{m}$. (b) Percentage of cells with nuclear alterations in control fibroblasts and those bearing LMNA mutations or treated with PIs, at passages 1-12. Each count was performed on DAPI-stained cells (130-200 cells) visualized by immunofluorescence microscopy $(\times 40$ magnification). DMSO treatment $(0.01 \%)$ did not increase the number of dysmorphic nuclei in control fibroblasts. Results are expressed as mean \pm S.E.M.

fibroblast lysates, it was markedly increased in fibroblasts from the six patients with $L M N A$ mutations and in cells treated with indinavir or nelfinavir (Figure 2a), but not with the nonpeptidomimetic PI atazanavir (data not shown). Prelamin A was also detected as an additional band with retarded electrophoretic mobility in both cells with LMNA mutations or treated with PIs by probing the Western blot with an anti-lamin antibody that recognizes both lamin A/C and prelamin A (SC$7292,{ }^{31}$ ) (Figure 2a). Immunofluorescence studies indicated that prelamin A accumulated at the nuclear rim, predominantly in the nuclear herniations (Figure $2 b$ and data not shown). Prelamin A was also observed in lysates of subcutaneous 


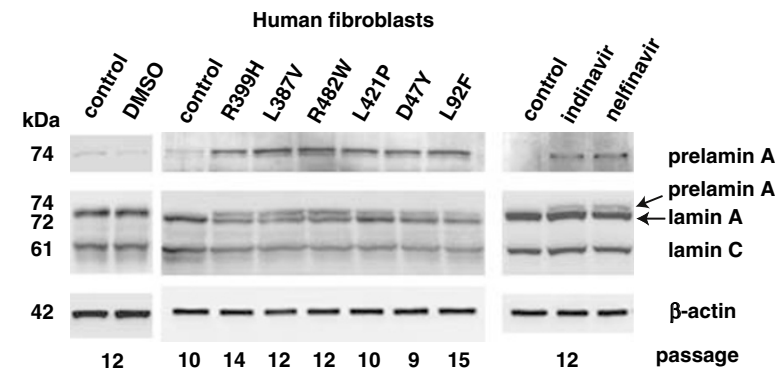

b
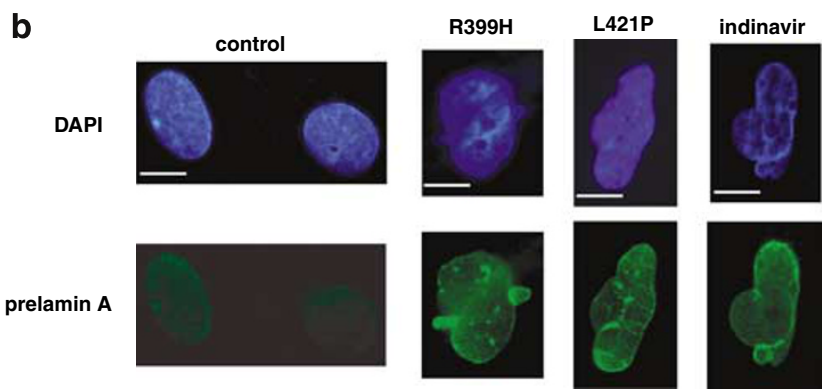

C

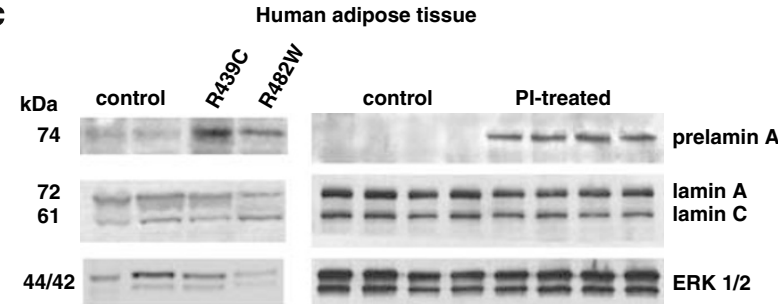

Figure 2 Prelamin $\mathrm{A}$ and lamin $\mathrm{A} / \mathrm{C}$ expression in fibroblasts with $L M N A$ mutations or treated with PIs (a), and in patients' adipose tissue (C). (a) Fibroblast lysates were submitted to Western blot as described in Materials and methods. Antibody SC-6214 (upper blot) specifically recognized prelamin A, whereas antibody SC-7292 (central blot) revealed mature forms of lamin A and C, and prelamin $A$ as a band with retarded mobility. Beta-actin was used as an index of the cellular protein level. DMSO treatment $(0.01 \%)$ did not induce prelamin A accumulation in control fibroblasts. Representative blots (performed in triplicate) are shown. Cell culture passages are indicated. (b) Prelamin A expression was studied by immunofluorescence microscopy (SC-6214 antibody) in control fibroblasts and those bearing LMNA mutations or treated with PIs. The data obtained at passage 7 are shown, along with representative cells. Scale bars represent $10 \mu \mathrm{m}$. (c) Patients' adipose tissue lysates were immunoblotted with antibodies directed against prelamin A (SC-6214), lamin A/C (MAB-3211) and ERK 1/2 (as an index of protein level)

adipose tissue from two patients bearing $L M N A$ mutations and from four HIV-infected patients under treatment including indinavir or nelfinavir, but not in adipose tissue lysates from healthy subjects (Figure 2c). LMNA mutations and $\mathrm{PI}$ treatment did not alter the amount of lamin $A / C$, both in fibroblasts and adipose tissue (Figure $2 \mathrm{a}$ and $\mathrm{c}$ ).

LMNA mutations and $\mathrm{PI}$ treatment reduce the proliferative and replicative capacity of cultured fibroblasts. The population doubling level (PDL) of untreated control fibroblasts remained stable up to passage 16 , at $2.69 \pm 0.05$ (Figure $3 a$ ). In contrast, the proliferation rate of fibroblasts with LMNA mutations or treated with PIs decreased rapidly. Half-maximal inhibition of PDL and arrest of cell division $(\mathrm{PDL}<0.5)$ were observed between passages

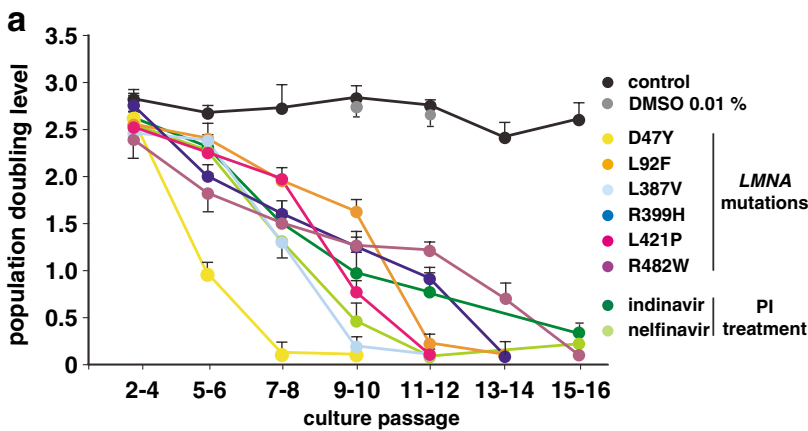

b

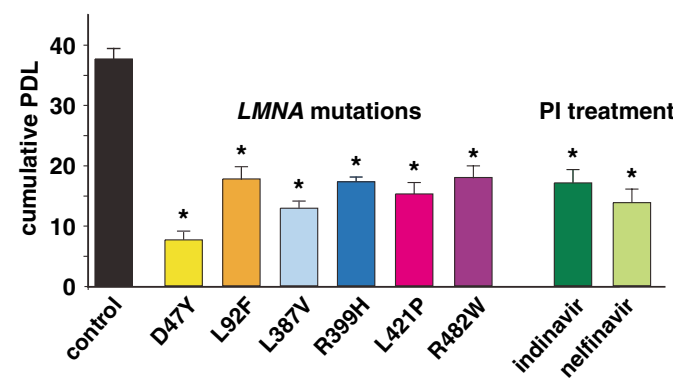

Figure 3 Reduced proliferative activity in fibroblasts with LMNA mutations or treated with PIs. (a) The PDL was calculated as stated in Materials and methods. DMSO treatment $(0.01 \%)$ of control fibroblasts did not alter PDL value. Mean PDL values $( \pm$ S.E.M. $)$ at the indicated passages are shown. Experiments were performed in triplicate. (b) Cumulative PDL (mean \pm S.E.M., culture passages 1-16) of control fibroblasts and those with LMNA mutations or treated with PIs. ${ }^{*} P<0.05$ versus control

10 and 14 or between passages 5 and 10 in fibroblasts with LMNA mutations or treated with PIs, respectively, apart from D47Y-mutated cells, which stopped proliferating at passage 7. Consistent with these results, the cumulative PDL (CPDL) was significantly and similarly reduced, by $50-60 \%$, in fibroblasts with LMNA mutations or treated with PIs, except for those bearing the D47Y mutation (80\% decrease) (Figure 3b).

LMNA mutations and PI treatment also induced a striking decrease in fibroblasts' replicative capacity, measured in terms of bromodeoxyuridine (BrdU) incorporation in halfconfluent cells (Figure 4a). Interestingly, most of these BrdUnegative fibroblasts were enlarged and flattened, with abnormally shaped nuclei-morphologic changes typically associated with senescence (Figure 4a). Positive and negative controls of BrdU incorporation were obtained by treating fibroblasts with activators (insulin $10^{-6} \mathrm{M}$ and fetal bovine serum (FBS) $20 \%, 24 \mathrm{~h}$ ) or with an inhibitor (etoposide $20 \mu \mathrm{M}, 12 \mathrm{~h}$ ) of proliferation, thus confirming the sensitivity of the replication assay (Figure $4 a$ ).

Apoptotic cells identified by flow cytometry represented less than $4 \%$ of total cells in fibroblasts with $L M N A$ mutations or treated with PIs and in control fibroblasts (Figure 4b). Moreover, Western blots from whole-cell lysates showed no evidence of caspase 3-mediated PARP proteolysis (Figure 4b), a strong indicator of apoptosis. At late passages (passage 16), PARP lysis was slightly increased in PI-treated cells and in some, but not all, patients' fibroblasts (data not shown). 

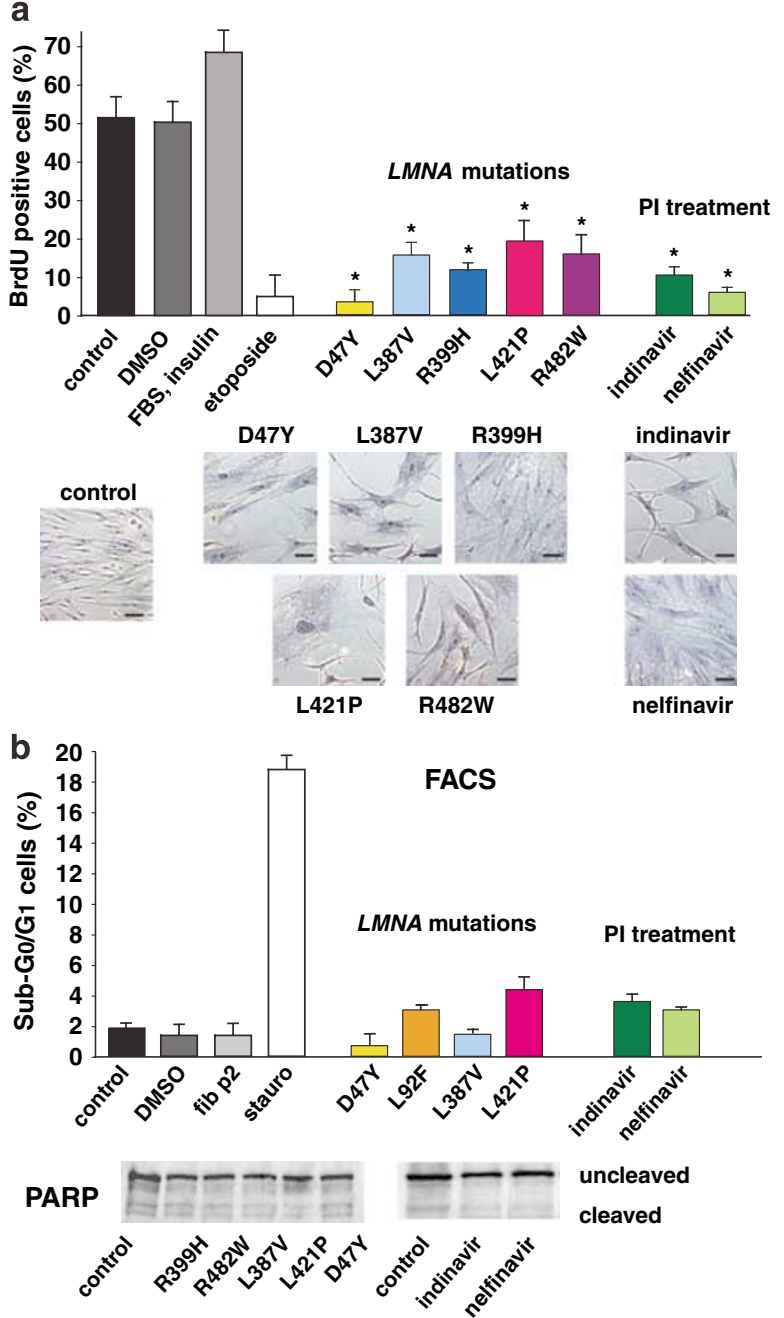

Figure 4 Reduced replicative capacity in fibroblasts with LMNA mutations or treated with PIs, as assessed by BrdU staining (a) with no evidence of apoptosis (b) (a) BrdU staining was performed on half-confluent fibroblasts (in triplicate) as indicated in Materials and methods and examined by phase microscopy. The percentage of dividing cells at passage 9-10 was assessed by counting total and BrdU-stained cells. DMSO treatment $(0.01 \%)$ of control fibroblasts did not alter BrdU incorporation. The sensitivity of the BrdU incorporation assay was confirmed by incubating control fibroblasts at passage 9 with activators (insulin $10^{-6} \mathrm{M}$ and FBS $20 \%$ ) or an inhibitor (etoposide) of proliferation, that respectively increased or decreased BrdU incorporation. Results are means \pm S.E.M. ${ }^{*} P<0.05$ versus control. Note the altered cell number and morphology of fibroblasts with LMNA mutations or treated with Pls (passage 9). Scale bars represent $40 \mu \mathrm{m}$. (b) Apoptosis was assessed as the percentage of cells in sub-G0/G1 cellular phase by FACS analysis and by caspase 3-mediated PARP proteolysis on Western blot at passages 5-7. Apoptosis was less than $4 \%$ of total cell and not significantly different in control fibroblasts versus those with LMNA mutations or treated with PIs $(P>0.05)$. A positive control of apoptosis was obtained by incubating control fibroblasts (passage 9) for $20 \mathrm{~h}$ with the inductor of apoptosis, staurosporine $(500 \mathrm{nM})$. Young control fibroblasts (at passage 2) have been used as negative controls of apoptosis. Results are mean \pm S.E.M.

$\mathrm{P} 16^{\mathrm{INK} 4 \mathrm{a}}$ and $\mathrm{P} 21^{\mathrm{WAF}-1}$ protein expression is increased in fibroblasts with LMNA mutations or treated with PIs and in patients' adipose tissue. $\mathrm{P} 16^{\mathrm{INK} 4 \mathrm{a}}$ and $\mathrm{p} 21^{\mathrm{WAF}-1}$, two cell cycle checkpoint inhibitors that participate in the setup of the senescence program, ${ }^{30}$ were overexpressed by a
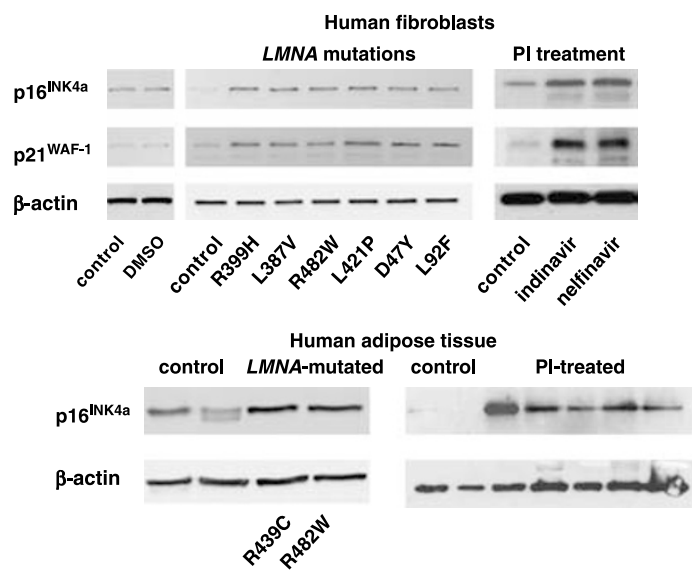

b SA- $\beta$ galactosidase activity
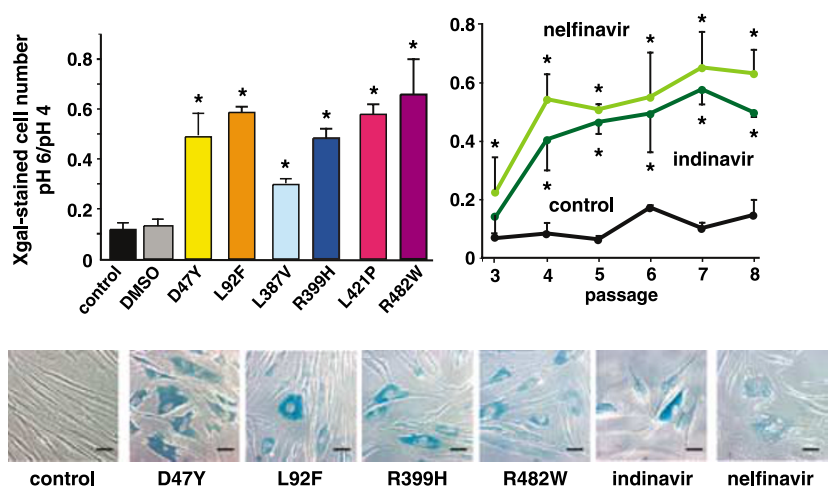

Figure 5 Premature senescence of fibroblasts with LMNA mutations or treated with PIs and patients' adipose tissue. (a) Overexpression of markers of cell cycle arrest. Fibroblast and adipose tissue lysates were submitted to Western blot as described in Materials and methods. Beta-actin was used as an index of the cellular protein level. Representative blots of fibroblasts with LMNA mutations (passages 915 ) or treated with PIs (passage 10) performed in triplicate are shown. DMSO treatment $(0.01 \%)$ did not increase p16 or p21 protein expression in control fibroblasts. (b) SA- $\beta$-galactosidase activity. Physiological lysosomal and SA- $\beta$ galactosidase activities were assessed by cellular $\mathrm{X}$-gal blue staining at $\mathrm{pH} 4$ and $\mathrm{pH} 6$, respectively. The ratio of $\mathrm{pH} 6$ - to $\mathrm{pH}$ 4-positive blue cells, which specifically characterizes SA- $\beta$-galactosidase activity, was calculated after microscopic examination of 500 cells at passage $6-7$ for fibroblasts with $L M N A$ mutations and at each indicated passage for PI-treated cells. DMSO treatment $(0.01 \%)$ did not increase SA- $\beta$-galactosidase activity in control fibroblasts. Results are mean \pm S.E.M. ${ }^{*} P<0.05$ versus control. Representative micrographs of cells stained with $\mathrm{X}$-gal at $\mathrm{pH} 6$ are shown. Note the senescence-associated flattened and enlarged morphology of cells with LMNA mutations or treated with PIs, and their nuclear alterations. Scale bars represent $40 \mu \mathrm{m}$

$250-400 \%$ in fibroblasts bearing $L M N A$ mutations or treated with Pls at passages $9-15$ (Figure $5 \mathrm{a}$ ). The $\mathrm{p} 16^{\mathrm{INK} 4 \mathrm{a}}$ protein level was also increased in adipose tissue lysates from lipodystrophic patients with $L M N A$ mutations or under $\mathrm{PI}$ treatment, as compared to healthy subjects (Figure 5a).

Fibroblasts with LMNA mutations or treated with PIs prematurely acquire a senescent phenotype. Strong cellular staining for 5-bromo-4-chloro-3-indolyl- $\beta$-Dgalactoside $(\mathrm{X}$-gal) at $\mathrm{pH} 4$, indicating physiological lysosomal $\beta$-galactosidase activity, was detected in control fibroblasts and in those bearing $L M N A$ mutations or treated 
with PIs (data not shown). In contrast, SA- $\beta$-galactosidase activity, assessed at $\mathrm{pH} 6$, was absent in control cells up to passage 14, but present, even at early passages, in fibroblasts with $L M N A$ mutations or treated with PIs (Figure $5 \mathrm{~b}$ and data not shown). X-gal-stained fibroblasts with LMNA mutations were present at passage 4 and their number increased moderately thereafter (Figure 5b). Indinavir and nelfinavir both rapidly induced a 40- to 60-fold increase in the number of blue X-gal-stained cells at $\mathrm{pH} 6$, accounting for $35-65 \%$ of total cells at passage 4 (Figure $5 \mathrm{~b}$ ). No SA- $\beta$-galactosidase activity was observed in control fibroblasts studied until passage 14 (Figure $5 \mathrm{~b}$ and data not shown). Microscopic examination showed that the fibroblasts with $L M N A$ mutations or treated with PIs that were stained with $\mathrm{X}$-gal at $\mathrm{pH} 6$ also harbored the morphologic alterations that characterize senescent cells, and that most of them had an altered nuclear structure (Figure $5 b$ ).

Fibroblasts with LMNA mutations or treated with PIs and patients' adipose tissue show mitochondrial alterations. As mitochondria are key actors in cellular ageing, ${ }^{26,27}$ we examined whether the expression of respiratory chain proteins was altered by $L M N A$ mutations or $\mathrm{PI}$ treatment. As shown in Figure 6a, expression of the mitochondrial DNA-encoded subunit II of the cytochrome oxidase complex IV (COX2), but not of the nuclear DNAencoded subunit IV of the same complex (COX4), was strikingly decreased in fibroblasts bearing $L M N A$ mutations
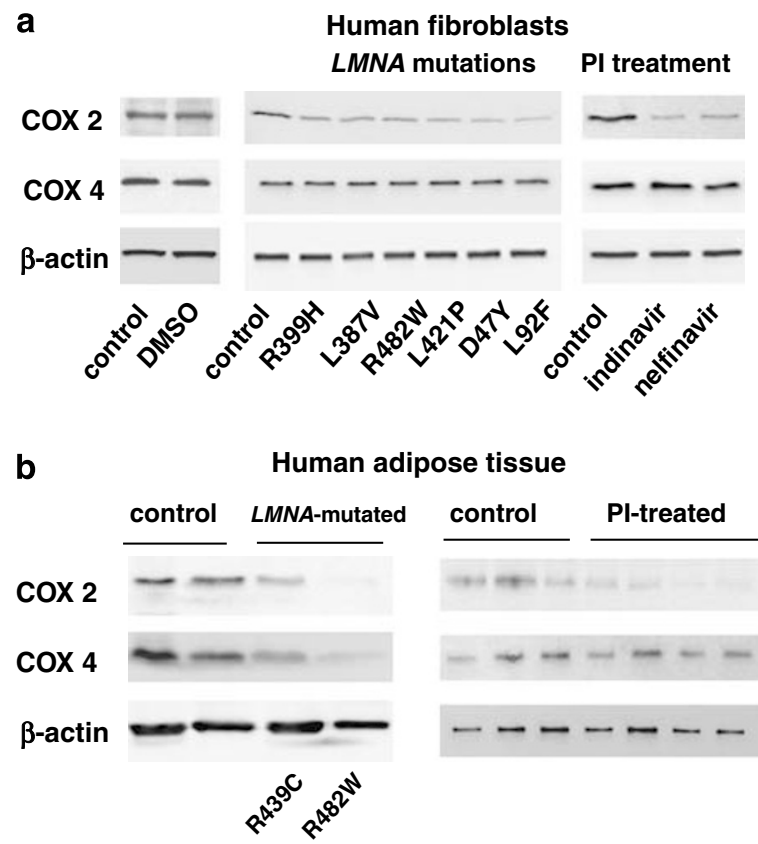

Figure 6 LMNA mutations and PI treatment induce mitochondrial alteration in human fibroblasts and adipose tissue. Western blots of fibroblast (upper panels) and adipose tissue (lower panels) lysates were revealed with antibodies directed against the mitochondrial proteins COX2 and COX4, as indicated. Beta-actin was used as an index of the cellular protein level. DMSO treatment $(0.01 \%)$ did not alter COX2 or COX4 protein expression in control fibroblasts. Representative blots (from triplicate experiments) from LMNA-mutated (passages 9-15) and PI-treated (passage 10) fibroblasts (upper panels) and of patients' adipose tissue (lower panels) are shown or treated with PIs, as compared with control cells. In adipose tissue samples from patients with LMNA mutations or under $\mathrm{PI}$ treatment, COX2 expression was lower than in control samples (Figure 6b). COX4 expression was not modified in fat samples from lipodystrophic HIV-infected patients, although it was decreased in parallel with COX2 in adipose tissue from patients with LMNA mutations. Consistent with Pl-induced mitochondrial dysfunction, we observed that longterm treatment of cultured fibroblasts (passages 9-13) with indinavir or nelfinavir significantly decreased (by 30-35\%) the mitochondrial membrane potential assessed by the JC-1 (5,5',6,6'-tetrachloro-1,1', 3,3'-tetraethyl-benzimidazolo carbocyanine iodide) aggregate to monomer ratio (control: $5.48 \pm 0.56$; indinavir: $3.65 \pm 0.51, P=0.0011$; nelfinavir: $3.82 \pm 0.52, P=0.0041, n=6)$.

Production of ROS is increased in fibroblasts with LMNA mutations or treated with Pls. ROS are strong inducers of replicative senescence and are produced in excess by defective mitochondria. ${ }^{23-26}$ ROS production was evaluated indirectly by measuring the oxidation status of the permeant derivatives $\mathrm{CM}-\mathrm{H}_{2}$ DCFDA and the reduction of nitroblue tetrazolium (NBT). As depicted in Figure 7a, dichlorofluorescein oxidation was increased two- to fivefold in fibroblasts with LMNA mutations at passages 6-8, as compared to control cells. PI-treated fibroblasts also had a higher redox status than control fibroblasts, as shown by a twofold increase in $\mathrm{CM}-\mathrm{H}_{2}$ DCFDA oxidation at passages 3-4 (Figure 7a). The $\mathrm{PI}$ effects were maximal at passage 10 (four- to fivefold increase over control). ROS hyperproduction in PI-treated fibroblasts was confirmed by measuring NBT reduction, which was significantly increased at all passages tested (Figure 7a).

Microscopic examination (Figure 7b) confirmed the increased production of ROS in fibroblasts with LMNA mutations and treated with PIs, as compared to control fibroblasts. $\mathrm{CM}-\mathrm{H}_{2}$ DCFDA fluorescence was enhanced in the typically senescent fibroblasts whose cytoplasm was enlarged and flattened. Moreover, mitochondria staining of senescent fibroblasts, assessed by MitoTracker Red 580 probe (MTR) red fluorescence, colocalized with $\mathrm{CM}-\mathrm{H}_{2}$ DCFDA fluorescence (Figure $7 \mathrm{~b}$ ), suggesting that mitochondria were the main source of ROS.

Inhibition of farnesylation prevents excessive ROS production and cellular senescence in fibroblasts with LMNA mutations or treated with PIs. To test whether prelamin A farnesylation could account for oxidative stress and premature senescence, we incubated control fibroblasts and those with LMNA mutations or treated with PIs (passages 4-6) with the highly potent and selective inhibitor of farnesyl transferases (FTI)-277 32 or the isoprenoid synthesis inhibitor mevinolin (data not shown). We verified the efficiency of the drugs by studying HDJ-2, a farnesylated CaaX protein whose electrophoretic mobility is retarded when farnesylation is inhibited. ${ }^{32}$ We indeed observed that $50-60 \%$ of HDJ-2 was unfarnesylated in lysates from cells treated with $\mathrm{FTI}-277$ or mevilonin (Figure 8a and data not shown). 
a
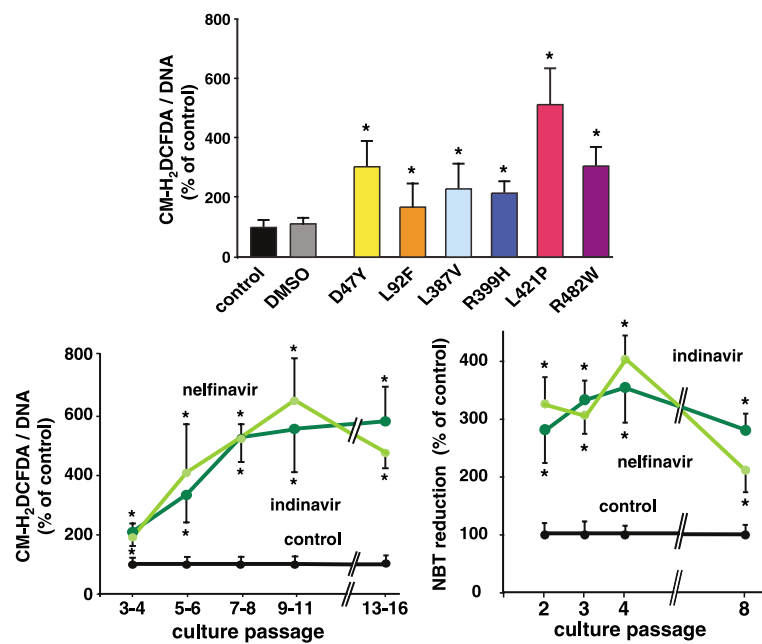

b

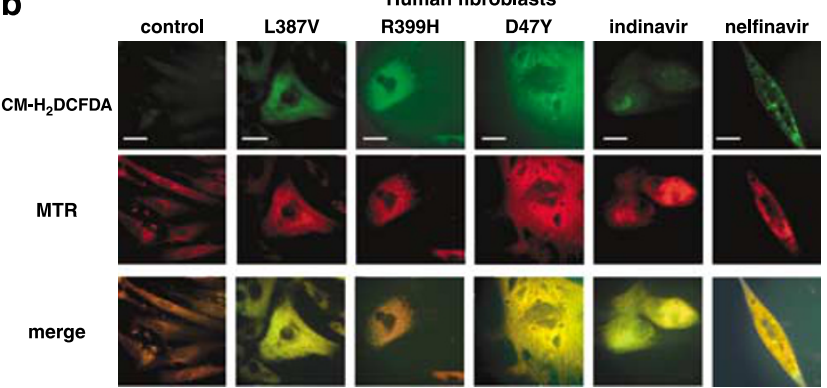

Figure 7 Increased production of ROS in fibroblasts with LMNA mutations or treated with PIs. (a) ROS production was assessed in terms of the oxidation of CM$\mathrm{H}_{2}$ DCFDA derivatives (at $520 \mathrm{~nm}$ ) and normalized to the DNA content. CM$\mathrm{H}_{2}$ DCFDA/DNA was assessed at passages $6-8$ in fibroblasts with $L M N A$ mutations and at each indicated passage for PI-treated fibroblasts. DMSO treatment $(0.01 \%)$ did not alter ROS production in control fibroblasts. In PI-treated fibroblasts, ROS production was also measured in terms of the reduction of NBT. Experiments were performed in triplicate. Results are mean \pm S.E.M. ${ }^{*} P<0.05$. (b) Cells were stained using the $\mathrm{CM}-\mathrm{H}_{2} \mathrm{DCFDA}$ derivatives (ROS-induced oxidation results in green labeling) and the fluorescent mitochondrial marker MitoTracker Red MTR (red labeling) and were examined by fluorescence microscopy. The predominant perinuclear mitochondrial staining of control cells was lost in fibroblasts treated with PIs or bearing LMNA mutations. Merged images show the colocalization of mitochondria and ROS production. Scale bars represent $20 \mu \mathrm{m}$

As expected, FTI treatment increased the level of prelamin A in all fibroblasts, bearing or not $L M N A$ mutations, or treated or not with PIs (Figure 8a), consistent with the accumulation of the unfarnesylated form of prelamin A. In control cells, the FTIinduced accumulation of unfarnesylated prelamin $A$ had no impact on $16^{\mathrm{INK} 4}$ expression (Figure 8a), ROS production (Figure $8 \mathrm{~b}$ ) and SA- $\beta$-galactosidase activity (Figure $8 \mathrm{c}$ ). In fibroblasts with $L M N A$ mutations or treated with PI, FTI-277, and to a lesser extent, mevinolin (data not shown) treatments strikingly decreased $\mathrm{p} 16^{\mathrm{INK} 4}$ and ROS overproduction (Figure $8 \mathrm{a}$ and $\mathrm{b}$ ) and SA- $\beta$-galactosidase activity (Figure 8c), consistent with the reduction of the toxic farnesylated form of prelamin A.

These data strongly suggest that increased oxidative stress and premature senescence in both fibroblasts with LMNA mutations or treated with PIs may result, at least in part, from the toxicity of unproperly processed farnesylated prelamin A.

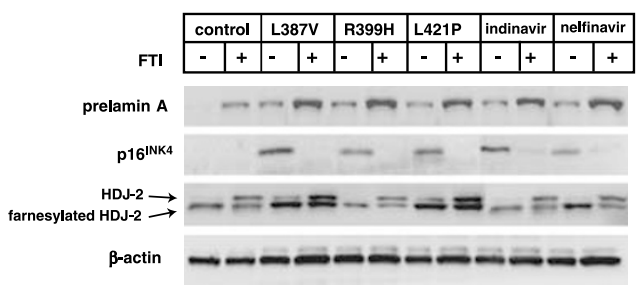

b

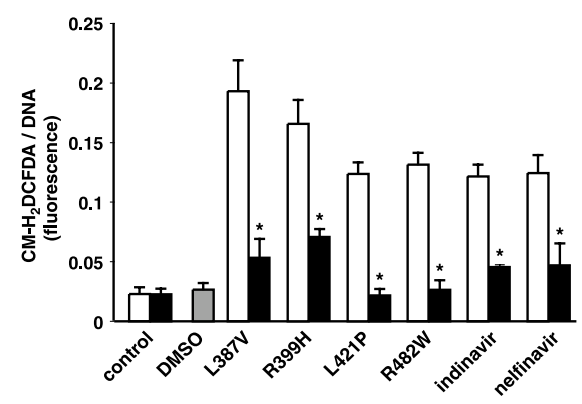

C

SA- $\beta$-galactosidase activity

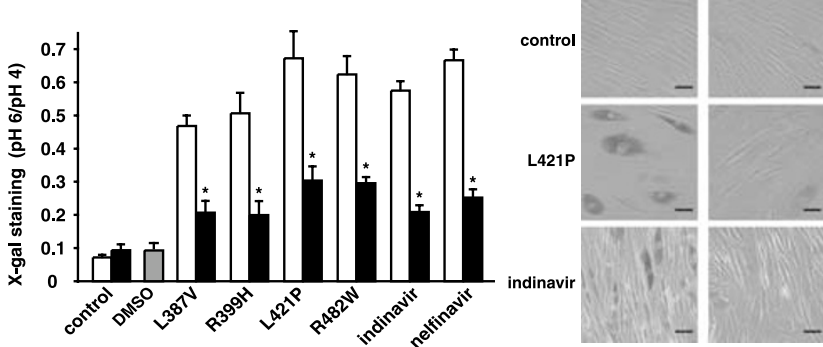

Figure 8 Inhibition of farnesylation prevents ROS production and cellular senescence in fibroblasts with LMNA mutations or treated with PIs. Control fibroblasts and those with LMNA mutations or treated with PIs (passages 4-6) were incubated with the FTI-277 (20 $\mu \mathrm{M}$ for $48 \mathrm{~h})$ or with $0.1 \%$ DMSO, as indicated in Materials and methods. All experiments were repeated three times. (a) Fibroblast lysates were submitted to Western blot using the indicated antibodies. Prelamin A was revealed with the SC-6214 antibody. The electrophoretic mobility of the protein HDJ-2, which is retarded when the protein is unfarnesylated, gave an index of global farnesylation processes. Representative blots are shown. (b) ROS production, assessed by oxidation of $\mathrm{CM}-\mathrm{H}_{2}$ DCFDA derivatives, was normalized to the DNA content in the absence (empty bars) or presence (dark bars) of FTI-277 treatment. DMSO at $0.1 \%$ did not increase ROS production. Results are mean \pm S.E.M. ${ }^{*} P<0.05$ versus non-FTI-treated cells. (c) The ratio of $\mathrm{X}$-gal cellular staining at $\mathrm{pH} 6$ and $\mathrm{pH} 4$, quantified at $630 \mathrm{~nm}$, specifically characterizes SA- $\beta$-galactosidase activity in the absence (empty bars) or presence (dark bars) of FTI-277 treatment. DMSO at $0.1 \%$ did not increase SA- $\beta$-galactosidase activity. Results are mean \pm S.E.M. ${ }^{*} P<0.05$ versus non-FTI-treated cells. Representative micrographs of cells stained with X-gal at pH 6 in the absence or presence of FTI-277 treatment are shown. Scale bars represent $40 \mu \mathrm{m}$

\section{Discussion}

Lipodystrophic syndromes associated with $L M N A$ mutations and HIV antiretroviral treatment share major clinical and biological features. Both disorders mainly affect peripheral fat, whereas central adipose tissue is frequently hypertrophic. Metabolic features include hypertriglyceridemia, insulin resistance, altered glucose tolerance, early cardiovascular complications and hepatic disorders. ${ }^{9,33}$ LMNA-linked lipodystrophy syndromes and premature ageing also share several clinical similarities, ${ }^{2-5}$ and HIV-infected patients on 
antiretrovirals have a significantly increased risk of ageingassociated comorbidities. ${ }^{10}$

By using cultured fibroblasts, we observed further similarities between alterations associated with LMNA mutations or HIV antiretroviral treatment. Indeed, nuclear shape and lamina composition were similarly altered and the prevalence of dysmorphic nuclei during cell passages increased similarly, pointing to the existence of common underlying pathophysiological mechanisms.

Our study shows that prelamin A accumulation, predominantly at the nuclear rim, is a common feature of fibroblasts with $L M N A$ mutations or treated with PIs. The interaction between A- and B-type lamins is altered in both situations, pointing to a defective setup of the lamina meshwork, that has been already described in HGPS cells. ${ }^{4,5,8,11}$ The increased amount of prelamin $A$ in adipose tissue samples from lipodystrophic patients bearing LMNA mutations or treated with PIs indicates that prelamin A accumulation is occuring in vivo. Moreover, lipodystrophy itself could result from defective prelamin A processing, as sterol-regulatory element-binding protein-1, which contributes to adipogenesis, is sequestrated at the nuclear rim in cells with other LMNA mutations ${ }^{7}$ and in preadipocytes chronically treated with $\mathrm{PIs},{ }^{21}$ thereby impairing adipocyte differentiation. However, the role of lamin $A$ in adipocyte differentiation is unclear. ${ }^{20,34}$

We obtained several lines of evidence suggesting that prelamin A accumulation is associated with signs of premature senescence both in fibroblasts and adipose tissue. First, proliferative and replicative activities were similarly decreased in fibroblasts with LMNA mutations or treated with PIs, an effect independent of apoptosis. Second, the cyclindependent kinase inhibitors $\mathrm{p} 16^{\mathrm{INK} 4 \mathrm{a}}$ and $\mathrm{p} 21^{\mathrm{WAF}-1}$, which mediate cell cycle arrest through retinoblastoma protein phosphorylation, ${ }^{30}$ were overexpressed. Upregulation of p21 and other p53 target genes has previously been observed in tissues from Zmpste24-knockout mice. ${ }^{35}$ Third, typical morphologic features of senescent cells and specific SA- $\beta$ galactosidase activity were observed in fibroblasts with LMNA mutations or treated with Pls, but not in control cells.

The pathophysiology of laminopathies with premature ageing is thought to result from the retention of unprocessed farnesylated prelamin A. Prelamin A maturation is a complex process, involving the addition of a farnesyl group to the Cterminal tail, with secondary enzymatic release by the zinc metalloprotease Zmpste24 (reviewed by Mattout et al ${ }^{1}$ ). Due to the efficiency of the enzymatic machinery, prelamin $A$ is virtually undetectable in wild-type or untreated cells. LMNA mutations leading to a deleted Zmpste24 cleavage site and ZMPSTE24 mutations, both by directly blocking proteolysis of farnesylated prelamin $A$, result in severe premature ageing phenotypes in humans ${ }^{4,5,31}$ and mice. ${ }^{35,36}$ Interestingly, prelamin A accumulation has also been reported in fibroblasts from patients with familial partial lipodystrophy of the Dunnigan type ( $L M N A$ mutation $\mathrm{R} 482 \mathrm{~L}$ ) and atypical progeroid syndromes ( $L M N A$ mutations $\mathrm{R} 527 \mathrm{H}$ and S143F), but not from a patient with muscular dystrophy due to the R401C substitution. ${ }^{7}$ Indeed, phenotypes of laminopathies with lipodystrophy, insulin resistance and/or premature ageing are clinically related. ${ }^{2-5}$ The defective prelamin A processing associated with different heterozygous substitutions in the protein could result from an altered recognition of the mutated prelamin $\mathrm{A}$ by the Zmpste24 protease. ${ }^{7}$ The present data, observed with other LMNA mutations responsible for insulin resistance and/or lipodystrophy (D47Y, L92F, L387V, R399H, L421P and R482W), are in agreement with this hypothesis. In fibroblasts treated with the PIs indinavir and nelfinavir, we propose that impaired prelamin A proteolytic maturation could be due to an inhibitory effect of these drugs on the activity of the metalloprotease Zmpste24. Thus, farnesylated prelamin A accumulation is probably the initial event, shared by cells with $L M N A$ mutations or treated with indinavir and nelfinavir, that triggers premature ageing. Interestingly, treating the cells with atazanavir, a nonpeptidomimetic PI, did not induce prelamin $A$ accumulation, thus reinforcing the concept that structural determinants in the PI molecules might be involved in Zmpste24 inhibition.

FTI prevent cellular senescence in fibroblasts from patients with HGPS, strongly arguing for the cellular toxicity of the farnesylated species of prelamin A (reviewed by Young et $a l^{11}$ ). In addition, the replacement of a lamin A/C-encoding allele by a lamin C-only allele ${ }^{13}$ or a lamin A/C-knockout allele $^{12}$ in Zmpste24-deficient mice, or the treatment with FTI of mice with $L M N A$-linked progeria, ${ }^{17,18}$ both reduce the cellular amount of farnesylated prelamin A and significantly improve the progeroid syndrome. The retention of a farnesylated $\mathrm{C}$ terminus is thought to act in a dominant-negative way by becoming permanently anchored to the nuclear membrane, thereby impairing physiological lamin A oligomerization and resulting in cellular ageing. ${ }^{11}$ In fibroblasts with $L M N A$ mutations or treated with PIs, the reversion of $\mathrm{p} 16^{\mathrm{INK} 4 \mathrm{a}}$ overexpression and SA- $\beta$-galactosidase activity by inhibition of farnesylation is a strong argument in favor of the pathophysiological role of accumulated farnesylated prelamin $A$ in premature senescence.

The free-radical theory of ageing links ROS hyperproduction with mitochondrial dysfunction, most toxic ROS being byproducts of mitochondrial oxidative phosphorylation and activation of cellular stress pathways. ${ }^{23,26}$ We observed that ROS production was markedly enhanced in fibroblasts with LMNA mutations or treated with PIs. This state of oxidative stress was associated with alterations in the expression of respiratory chain proteins and with a decrease of mitochondrial membrane potential in PI-treated fibroblasts. These defects, together with the colocalization of ROS and mitochondria, are in favor of the mitochondrial origin of the excess ROS in these cells. A vicious circle involving ROS production might reinforce the mitochondrial defects and promote the accumulation of lipid and protein peroxidation products. $^{37}$ ROS accumulation can also result from and activate cellular stress pathways that participate in cell growth arrest. ${ }^{23}$ Furthermore, ROS can trigger DNA damage, and a defective DNA repair response has been shown to be an important pathophysiological mechanism in premature ageing linked to genetically altered prelamin A maturation. ${ }^{38}$ Interestingly, our results using inhibitors of farnesylation argue for a role of farnesylated prelamin $A$ in the increase of cellular ROS. Further studies exploring the precise mechanisms that link farnesylated prelamin A and ROS production are needed.

Mitochondrial alterations and ROS hyperproduction have not previously been described in cells bearing $L M N A$ 
mutations. In addition, the findings that some PIs induce mitochondrial dysfunction are novel, such alterations being generally attributed to nucleoside reverse transcriptase inhibitors (mainly thymidine analogs). ${ }^{39,40}$ In the treatment of HIV infection, both drugs are commonly associated, which could cause major mitochondrial alterations. Whether PIs or LMNA mutations can induce direct effects on isolated mitochondria needs further investigations.

In conclusion, we show here that both lipodystrophyassociated mutations in A-type lamins and indinavir and nelfinavir treatment favor the retention of cellular farnesylated prelamin $A$, which trigger oxidative stress and premature senescence. We propose that, in addition to their similar clinical and biological features, lipodystrophic syndromes resulting from LMNA mutations or HIV antiretroviral treatment share common pathophysiological mechanisms leading to premature ageing complications.

\section{Materials and Methods \\ Patients, cells and tissues. Six female patients with insulin resistance and/ or diabetes associated with abnormal body fat distribution, with lipoatrophy or android habitus, were referred to our laboratory for LMNA genetic testing. They were found to harbor the R482W mutation associated with familial partial lipodystrophy of the Dunnigan type (patient $\mathrm{P} 6)^{33}$ or previously undescribed heterozygous LMNA substitutions (D47Y, L92F, L387V, R399H, L421P). Only the patient with the LMNA D47Y mutation exhibited clinical signs of premature ageing. The precise clinical phenotype of these patients will be presented elsewhere. Primary skin fibroblast cultures were established after punch biopsy at ages 9,47 , $60,53,56$ and 51 years, respectively. Fibroblasts from two non-obese nondiabetic women aged 20 and 33 years undergoing plastic surgery were used as controls. \\ We also used subcutaneous abdominal adipose tissue samples from four HIV- infected lipoatrophic patients aged 39-53 years who were on antiretroviral regimens, including indinavir or nelfinavir, and from four HIV-seronegative, nondiabetic, 40- to 60-year-old controls, as described elsewhere. ${ }^{41}$ We have previously observed an altered morphology and mitochondrial dysfunction in fat tissue from these HIV-infected patients. ${ }^{41,42}$ Subcutaneous cervical adipose tissue from two lipodystrophic women aged 22 and 33 years and bearing the R482W and R439C LMNA mutations, respectively, was collected during plastic surgery. They were compared to subcutaneous abdominal adipose tissue surgical samples from two nondiabetic non-obese control women aged 20 and 42 years. All the subjects gave their written informed consent for these studies.}

Cell culture and treatment. Fibroblasts were grown in DMEM medium (Gibco ${ }^{\mathbb{R}}$ Cell Culture, Invitrogen Corporation, San Diego, CA, USA) containing $1 \mathrm{~g} / \mathrm{l}$ glucose, $20 \mathrm{mM}$ L-glutamine, $25 \mathrm{mM}$ Hepes, $110 \mathrm{mg} / \mathrm{ml}$ sodium pyruvate, $10 \% \mathrm{FBS}$ (PAA Laboratories, Les Mureaux, France), $100 \mathrm{U} / \mathrm{ml}$ penicillin and $0.1 \mathrm{mg} / \mathrm{ml}$ streptomycin (Invitrogen Corporation) at $37^{\circ} \mathrm{C}$ in $5 \% \mathrm{CO}_{2} / 95 \%$ air. Control fibroblasts were treated or not treated with Pls at $\mathrm{Cmax}$ concentrations (indinavir $10 \mu \mathrm{M}$, nelfinavir $5 \mu \mathrm{M}$ or atazanavir $4 \mu \mathrm{M})^{19,43}$ from passages 2-16. Indinavir was provided by Merck Sharp \& Dohme Laboratories (Clermond-Ferrand, France) and nelfinavir by Agouron Pharmaceuticals (San Diego, CA, USA). Atazanavir was kindly provided by Dr. Stéphane Azoulay (CNRS UMR 6001, Nice, France). Control fibroblasts or those with LMNA mutations or treated with PIs were incubated or not with the farnesylation inhibitors FTI-277 (Calbiochem, Darmstadt, Germany) $(20 \mu \mathrm{M}$ for $48 \mathrm{~h}$ ) or mevinolin (Sigma-Aldrich, Saint Louis, MO, USA) ( $25 \mu \mathrm{M}$ for $18 \mathrm{~h}$ ). In all experiments, fibroblasts with LMNA mutations or treated with Pls were compared to control cells cultured in parallel. Stock solutions of PIs and FTI-277 were prepared in dimethyl sulfoxide (DMSO). In PI-treated cells, the final concentrations of DMSO were $\leqslant 0.005 \%$, below the threshold of toxicity. ${ }^{19}$ Nevertheless, DMSO controls were performed on fibroblasts at passages 9-12, previously treated for 7 weeks or more by the solvent at $0.01 \%$ in each experiment. In FTI-treated cells, the final concentration of DMSO was $0.1 \%$. The effect of this concentration of solvent has been assessed in parallel on ROS production and SA- $\beta$-galactosidase activity.

Cell morphology and immunofluorescence microscopy. Fibroblasts grown on glass coverslips were fixed in cold methanol for $10 \mathrm{~min}$ at $-20^{\circ} \mathrm{C}$.
Antibodies directed against lamin A/C (MAB-3211, Chemicon International Inc. Temecula, CA, USA), lamin B (a generous gift from B. Buendia, UPMC, France) and prelamin A (SC-6214, Santa Cruz Biotechnology Inc., Santa Cruz, CA, USA) were revealed by using secondary antibodies coupled to Texas Red (Jackson ImmunoResearch Laboratories, West Grove, PA, USA) or fluorescein isothiocyanate (Santa Cruz Biotechnology). Cell nuclei were visualized after diamidino-2phenylindole hydrochloride (DAPI) staining. For each condition, 130-200 control, Pl-treated and LMNA-mutated cells were examined.

Western blot analysis. Cell extracts prepared as described previously ${ }^{21}$ were subjected to SDS-PAGE, blotted onto nitrocellulose membranes and probed with antibodies against lamin A/C (MAB-3211) or prelamin A (SC-6214, specific for prelamin $A$, and SC-7292, that recognizes both lamin $A / C$ and prelamin $A^{31}$ ). Antibodies against p16 $6^{\text {INK4a }}$, p21 ${ }^{\text {WAF-1 }}$ (ref 554070 and 556431, BD-Pharmingen, BD Biosciences, San Jose, CA, USA), COX2 and COX4 (ref A-6404 and A-21348, Molecular Probes, Eugene, OR, USA) and HDJ-2/DNAJ (MS-225-P0, Lab Vision Corporation, Fremont, CA, USA) were also used. The antibodies were detected with a chemiluminescence detection kit (GE-Healthcare, Saclay, France). Beta-actin (A5441, Sigma-Aldrich, St. Quentin Fallavier, France) or extracellular-regulated kinase (ERK) 1/2 (SC-93, Santa Cruz Biotechnology) were immunoprobed as indexes of the cellular protein level. Gel quantification was performed by using the ChemiGenius2 image analyser and software (Ozyme, St. Quentin en Yvelines, France).

PDL. The PDL was calculated as described by Martens et a $f^{44}$ as $\log _{2}\left(D / D_{0}\right)$, where $D_{0}$ and $D$ are the number of cells at seeding and harvesting, respectively. Senescence was considered complete when cells were unable to complete one PDL during a 4-week period, which included three consecutive weeks of refeeding with fresh $10 \%$ FBS. The CPDL was determined by adding the PDL values measured at each passage (1-16). Control fibroblasts did not reach replicative senescence at CPDL 66.

Cellular BrdU labeling. Dividing cells were identified by measuring BrdU incorporation according to the manufacturer's instructions (BrdU in situ detection kit, BD Biosciences Pharmingen, San Diego, CA, USA). Briefly, half-confluent cells were incubated for $16 \mathrm{~h}$ with $\mathrm{BrdU}(15 \mu \mathrm{M})$, then fixed and permeabilized. Anti-BrdU antibodies, streptavidin-HRP and the DAB substrate were then added successively for 60,30 and $5 \mathrm{~min}$, respectively. To obtain positive and negative controls of cell proliferation, half-confluent fibroblasts starved from FBS for $16 \mathrm{~h}$ were either treated with FBS $20 \%$ and insulin $10^{-6} \mathrm{M}$ for $24 \mathrm{~h}$, or with etoposide (Sigma-Aldrich) $20 \mu \mathrm{M}$ in complete medium for $12 \mathrm{~h}$. Dividing cells (red-brown), examined at $\times 20$ magnification, were counted in four randomly selected fields and expressed as a percentage of total cells

Cell apoptosis. Apoptosis was measured by means of flow cytometry and in terms of the cleavage of the death substrate PARP, as described previously. ${ }^{40}$ The percentage of apoptotic cells with subdiploid DNA staining, located in the 'sub-GO/ G1' peak, was measured. Positive control of apoptosis was obtained by treating starved fibroblasts with staurosporine (Sigma-Aldrich) $500 \mathrm{nM}$ for $20 \mathrm{~h}$. Caspase-3mediated PARP cleavage was estimated by Western blotting whole-cell lysates with an antibody (SC-7150, Santa Cruz Biotechnology) that recognizes the entire $(116000 \mathrm{Da})$ and cleaved $(85000 \mathrm{Da})$ forms of PARP.

SA- $\beta$-galactosidase assay. $\beta$-galactosidase activity at $\mathrm{pH} 6$ has been widely used as a biomarker of cellular senescence in vivo and in vitro. ${ }^{29}$ Cells on coverslips were fixed for $3-5 \mathrm{~min}$ at $22^{\circ} \mathrm{C}$ with $2 \%$ formaldehyde $/ 0.2 \%$ glutaraldehyde and incubated overnight at $37^{\circ} \mathrm{C}$ in $1 \mathrm{mg} / \mathrm{ml} \mathrm{X}$-gal, $40 \mathrm{mM}$ citric acid-sodium phosphate ( $\mathrm{pH} 6$ or 4), $5 \mathrm{mM}$ potassium ferricyanide, $5 \mathrm{mM}$ potassium ferrocyanide, $150 \mathrm{mM} \mathrm{NaCl}$ and $2 \mathrm{mM} \mathrm{MgCl}$. The blue-stained cells observed at $\mathrm{pH}$ 6 and pH 4 were counted in eight fields at $\times 20$ magnification (500 cells) and the ratio of $\mathrm{pH}$ 6- to $\mathrm{pH}$ 4-positive blue cells, which specifically represents SA- $\beta$ galactosidase activity, was calculated. Alternatively, blue X-gal cellular staining at $\mathrm{pH} 6$ and pH 4, dissolved in DMSO, was quantified at $630 \mathrm{~nm}$.

ROS production and mitochondrial markers. We used the $\mathrm{CM}$ $\mathrm{H}_{2}$ DCFDA derivatives (5- (and 6)-chloromethyl-2', $7^{\prime}$-dichlorodihydrofluorescein diacetate, acetyl ester, C6827, Molecular Probes) as cell-permeant indicators of ROS, the MitoTracker Red 580 probe (MTR, M-22425; Molecular Probes) as a marker of mitochondria and the cationic dye JC-1 (T-3168, Molecular Probes) as an 
indicator of mitochondrial membrane potential. ${ }^{40}$ Cells were cultured in 96-well plates, then washed and incubated with CM- $\mathrm{H}_{2} \mathrm{DCFDA}(9 \mu \mathrm{M}), \mathrm{JC}-1(4 \mu \mathrm{g} / \mathrm{ml})$, MTR $(50 \mathrm{nM})$ or Hoechst $33258(0.01 \mu \mathrm{g} / \mathrm{ml})$ in DMEM medium without FBS for 20 min at $37^{\circ} \mathrm{C}$ in the dark. Quantification was performed with a plate fluorescence reader (Spectrafluor Plus, Tecan-France, Trappes, France) at $520 \mathrm{~nm}\left(\mathrm{CM}-\mathrm{H}_{2} \mathrm{DCFDA}\right)$, 595 and $530 \mathrm{~nm}$ (JC-1 aggregates and monomers, respectively), $630 \mathrm{~nm}$ (MTR) and $460 \mathrm{~nm}$ (Hoechst 33258), respectively. ROS production was also detected by measuring the reduction of NBT (Sigma-Aldrich). Cells were incubated for $90 \mathrm{~min}$ in medium containing $0.2 \% \mathrm{NBT}$. Dark-blue reduced NBT, dissolved in DMSO, was assessed at $560 \mathrm{~nm}$. CM- $\mathrm{H}_{2}$ DCFDA $(20 \mu \mathrm{M})$ and MTR $(500 \mathrm{nM})$ in situ labeling was examined by fluorescence microscopy.

Statistical analysis. All experiments were performed at least three times on triplicate samples. All quantitative results were expressed as means \pm S.E.M. Comparisons between treated or mutated cells and control cells were made with Student's $t$-test. $P$-values $<0.05$ were considered significant.

Acknowledgements. We are grateful to patients who donated skin samples, without which this study would not have been possible. The authors thank Professor Véronique Martinot-Duquennoy, Dr. Marie-Christine Vantyghem and Dr. Aurélie Decaudain for providing surgical samples of adipose tissue from the R439C LMNAmutated patient and Michel Kornprobst for FACS analyses. This work was supported by grants from INSERM, Agence Nationale pour la Recherche sur le SIDA, Sidaction, Fondation pour la Recherche Médicale, ALFEDIAM/Laboratoires Servier and from European Union's FP6 Life Science, Genomics and Biotechnology for Health (LSHM-CT-2005-018690)

1. Mattout A, Dechat T, Adam SA, Goldman RD, Gruenbaum Y. Nuclear lamins, diseases and aging. Curr Opin Cell Biol 2006; 18: 335-341.

2. Caux F, Dubosclard E, Lascols O, Buendia B, Chazouilleres O, Cohen A et al. A new clinical condition linked to a novel mutation in lamins $A$ and $C$ with generalized lipoatrophy, insulin-resistant diabetes, disseminated leukomelanodermic papules, liver steatosis, and cardiomyopathy. J Clin Endocrinol Metab 2003; 88: 1006-1113.

3. Chen L, Lee L, Kudlow BA, Dos Santos HG, Sletvold O, Shafeghati $Y$ et al. LMNA mutations in atypical Werner's syndrome. Lancet 2003; 362: 440-445.

4. De Sandre-Giovannoli A, Bernard R, Cau P, Navarro C, Amiel J, Boccaccio I et al. Lamin a truncation in Hutchinson-Gilford progeria. Science 2003; 300: 2055.

5. Eriksson M, Brown WT, Gordon LB, Glynn MW, Singer J, Scott L et al. Recurrent de novo point mutations in lamin A cause Hutchinson-Gilford progeria syndrome. Nature 2003; 423 293-298.

6. Vigouroux C, Auclair M, Dubosclard E, Pouchelet M, Capeau J, Courvalin JC et al. Nuclea envelope disorganization in fibroblasts from lipodystrophic patients with heterozygous $\mathrm{R} 482 \mathrm{Q} / \mathrm{W}$ mutations in the lamin A/C gene. J Cell Sci 2001; 114: 4459-4468.

7. Capanni C, Mattioli E, Columbaro M, Lucarelli E, Parnaik VK, Novelli G et al. Altered pre-lamin A processing is a common mechanism leading to lipodystrophy. Hum Mol Genet 2005; 14: 1489-1502.

8. Goldman RD, Shumaker DK, Erdos MR, Eriksson M, Goldman AE, Gordon LB et al. Accumulation of mutant lamin $A$ causes progressive changes in nuclear architecture in Hutchinson-Gilford progeria syndrome. Proc Natl Acad Sci USA 2004; 101: 8963-8968.

9. Grinspoon S, Carr A. Cardiovascular risk and body-fat abnormalities in HIV-infected adults. N Engl J Med 2005; 352: 48-62

10. Senior K. Growing old with HIV. Lancet Infect Dis 2005; 5: 739

11. Young SG, Fong LG, Michaelis S. Prelamin A: Zmpste24, misshapen cell nuclei, and progeria-new evidence suggesting that protein farnesylation could be important for disease pathogenesis. J Lipid Res 2005; 46: 2531-2558.

12. Fong LG, Ng JK, Meta M, Cote N, Yang SH, Stewart CL et al. Heterozygosity for Lmna deficiency eliminates the progeria-like phenotypes in Zmpste24-deficient mice. Proc Nat Acad Sci USA 2004; 101: 18111-18116.

13. Fong LG, Ng JK, Lammerding J, Vickers TA, Meta M, Cote N et al. Prelamin A and lamin A appear to be dispensable in the nuclear lamina. J Clin Invest 2006; 116: 743-752.

14. Glynn MW, Glover TW. Incomplete processing of mutant lamin A in Hutchinson-Gilford progeria leads to nuclear abnormalities, which are reversed by farnesyltransferase inhibition. Hum Mol Genet 2005; 14: 2959-2969.

15. Capell BC, Erdos MR, Madigan JP, Fiordalisi JJ, Varga R, Conneely KN et al. Inhibiting farnesylation of progerin prevents the characteristic nuclear blebbing of Hutchinson-Gilford progeria syndrome. Proc Natl Acad Sci USA 2005; 102: 12879-12884.

16. Toth Jl, Yang SH, Qiao X, Beigneux AP, Gelb MH, Moulson CL et al. Blocking protein farnesyltransferase improves nuclear shape in fibroblasts from humans with progeroid syndromes. Proc Natl Acad Sci USA 2005; 102: 12873-12878.

17. Yang SH, Bergo MO, Toth JI, Qiao X, Hu Y, Sandoval S et al. Blocking protein farnesyltransferase improves nuclear blebbing in mouse fibroblasts with a targeted
Hutchinson-Gilford progeria syndrome mutation. Proc Natl Acad Sci USA 2005; 102 : 10291-10296.

18. Fong LG, Frost $D$, Meta $M$, Qiao X, Yang $\mathrm{SH}$, Coffinier $\mathrm{C}$ et al. A protein farnesyltransferase inhibitor ameliorates disease in a mouse model of progeria. Science 2006; 311: $1621-1623$

19. Caron M, Auclair M, Sterlingot H, Kornprobst M, Capeau J. Some HIV protease inhibitors alter lamin A/C maturation and stability, SREBP-1 nuclear localization and adipocyte differentiation. AIDS 2003; 17: 2437-2444.

20. Kudlow BA, Jameson SA, Kennedy BK. HIV protease inhibitors block adipocyte differentiation independently of lamin A/C. AIDS 2005; 19: 1565-1573.

21. Caron M, Auclair M, Vigouroux C, Glorian M, Forest C, Capeau J. The HIV protease inhibitor indinavir impairs sterol regulatory element-binding protein-1 intranuclear localization, inhibits preadipocyte differentiation, and induces insulin resistance. Diabetes 2001; 50: 1378-1388.

22. Harman $D$. The free radical theory of aging: the effect of age on serum mercaptan levels. J Gerontol 1960; 15: 38-40.

23. Dufour E, Larsson NG. Understanding aging: revealing order out of chaos. Biochim Biophys Acta 2004; 1658: 122-132.

24. Ben-Porath I, Weinberg RA. The signals and pathways activating cellular senescence. Int $J$ Biochem Cell Biol 2005; 37: 961-976.

25. Chen JH, Stoeber K, Kingsbury S, Ozanne SE, Williams GH, Hales CN. Loss of proliferative capacity and induction of senescence in oxidatively stressed human fibroblasts. J Biol Chem 2004; 279: 49439-49446.

26. Balaban RS, Nemoto S, Finkel T. Mitochondria, oxidants, and aging. Cell 2005; 120 : 483-495

27. Alexeyev MF, Ledoux SP, Wilson GL. Mitochondrial DNA and aging. Clin Sci (Lond) 2004; 107: $355-364$

28. Hayflick L, Moorhead PS. The serial cultivation of human diploid cell strains. Exp Cell Res 1961; 25: 585-621.

29. Dimri GP, Lee X, Basile G, Acosta M, Scott G, Roskelley C et al. A biomarker that identifies senescent human cells in culture and in aging skin in vivo. Proc Natl Acad Sci USA 1995; 92: 9363-9367.

30. Brookes S, Rowe J, Gutierrez Del Arroyo A, Bond J, Peters G. Contribution of p16(INK4a) to replicative senescence of human fibroblasts. Exp Cell Res 2004; 298: 549-559.

31. Navarro CL, Cadinanos J, De Sandre-Giovannoli A, Bernard R, Courrier S, Boccaccio I et al. Loss of ZMPSTE24 (FACE-1) causes autosomal recessive restrictive dermopathy and accumulation of Lamin A precursors. Hum Mol Genet 2005; 14: 1503-1513.

32. Adjei AA, Davis JN, Erlichman C, Svingen PA, Kaufmann SH. Comparison of potential markers of farnesyltransferase inhibition. Clin Cancer Res 2000; 6: 2318-2325.

33. Vigouroux C, Magré J, Vantyghem MC, Bourut C, Lascols O, Shackleton S et al. Lamin A/C gene: sex-determined expression of mutations in Dunnigan-type familial partial lipodystrophy and absence of coding mutations in congenital and acquired generalized lipoatrophy. Diabetes 2000; 49: 1958-1962.

34. Boguslavsky RL, Stewart CL, Worman HJ. Nuclear lamin A inhibits adipocyte differentiation: implications for Dunnigan-type familial partial lipodystrophy. Hum Mol Genet 2006; 15: 653-663.

35. Varela I, Cadinanos J, Pendas AM, Gutierrez-Fernandez A, Folgueras AR, Sanchez LM et al. Accelerated ageing in mice deficient in Zmpste24 protease is linked to p53 signalling activation. Nature 2005; 437: 564-568.

36. Bergo MO, Gavino B, Ross J, Schmidt WK, Hong C, Kendall LV et al. Zmpste24 deficiency in mice causes spontaneous bone fractures, muscle weakness, and a prelamin A processing defect. Proc Natl Acad Sci USA 2002; 99: 13049-13054.

37. von Zglinicki T, Nilsson E, Docke WD, Brunk UT. Lipofuscin accumulation and ageing of fibroblasts. Gerontology 1995; 41 (Suppl 2): 95-108.

38. Liu B, Wang J, Chan KM, Tjia WM, Deng W, Guan X et al. Genomic instability in laminopathy-based premature aging. Nat Med 2005; 11: 780-785

39. Brinkman K, Smeitink JA, Romijn JA, Reiss P. Mitochondrial toxicity induced by nucleoside-analogue reverse-transcriptase inhibitors is a key factor in the pathogenesis of antiretroviral-therapy-related lipodystrophy. Lancet 1999; 354: 1112-1115.

40. Caron M, Auclair M, Lagathu C, Lombes A, Walker UA, Kornprobst M et al. The HIV-1 nucleoside reverse transcriptase inhibitors stavudine and zidovudine alter adipocyte functions in vitro. AIDS 2004; 18: 2127-2136.

41. Bastard JP, Caron M, Vidal H, Jan V, Auclair M, Vigouroux $\mathrm{C}$ et al. Association between altered expression of adipogenic factor SREBP1 in lipoatrophic adipose tissue from HIV-1infected patients and abnormal adipocyte differentiation and insulin resistance. Lancet 2002: 359: 1026-1031.

42. Jan V, Cervera P, Maachi M, Baudrimont M, Kim M, Vidal H et al. Altered fat differentiation and adipocytokine expression are inter-related and linked to morphological changes and insulin resistance in HIV-1-infected lipodystrophic patients. Antivir Ther 2004; 9: 555-564.

43. Noor MA, Flint OP, Maa JF, Parker RA. Effects of atazanavir/ritonavir and lopinavir/ritonavir on glucose uptake and insulin sensitivity: demonstrable differences in vitro and clinically. AIDS 2006; 20: 1813-1821.

44. Martens UM, Chavez EA, Poon SS, Schmoor C, Lansdorp PM. Accumulation of shor telomeres in human fibroblasts prior to replicative senescence. Exp Cell Res 2000; 256: 291-299. 